\title{
Aa. Vv., Opinion. Voltaire. Nature and Culture
}

\section{Peter Balazs}

\section{OpenEdition}

\section{Journals}

\section{Édition électronique}

URL : http://journals.openedition.org/studifrancesi/8249

DOI : 10.4000/studifrancesi.8249

ISSN : 2427-5856

\section{Éditeur}

Rosenberg \& Sellier

\section{Édition imprimée}

Date de publication : 1 mai 2009

Pagination : 168-169

ISSN : 0039-2944

\section{Référence électronique}

Peter Balazs, «Aa. Vv., Opinion. Voltaire. Nature and Culture », Studi Francesi [En ligne], 157 (LIII | I) | 2009, mis en ligne le 30 novembre 2015, consulté le 12 janvier 2021. URL : http://journals.openedition.org/ studifrancesi/8249; DOI : https://doi.org/10.4000/studifrancesi.8249

\section{Ce document a été généré automatiquement le 12 janvier 2021.}

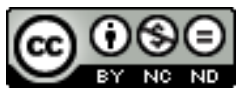

Studi Francesi è distribuita con Licenza Creative Commons Attribuzione - Non commerciale - Non opere derivate 4.0 Internazionale. 


\title{
Aa. Vv., Opinion. Voltaire. Nature and Culture
}

\author{
Peter Balazs
}

\section{RÉFÉRENCE}

Opinion. Voltaire. Nature and Culture, Oxford, Voltaire Foundation, 2007 («SVEC 2007:12»), pp. 307.

1 La première partie du volume, consacrée à «L'opinion au XVIII ${ }^{e}$ siècle», présentée par Ursula Haskins Gonthier, est composée de trois unités thématiques. La première de ces unités porte le titre «L'opinion et les périodiques». Les articles de Sébastien DROUIN (Les opinions des jésuites sur les sociniens, pp. 7-16) et de Marion LAFOUGE (Pour une critique aristocratique: Grimm et la "Correspondance littéraire", pp. 17-28) portent sur les rapports complexes existant entre l'opinion et les périodiques. Drouin met en relief comment et avec quelles conséquences les jésuites font des sociniens (choyés par les librespenseurs) un véritable ennemi à abattre, tandis que Lafouge analyse l'activité de littéraire critique que Grimm a exercée sur les pages de sa Correspondance, adressée à l'élite princière européenne.

2 Les trois articles suivants sont classés sous le titre «Les philosophes et l'opinion». L'étude de James HANRAHAN (Appealing and appearing to 'reason': Voltaire's political pamphlets of 1771 and the battle for public opinion, pp. 31-40) analyse les pamphlets de Voltaire composés pour soutenir le coup d'Etat de Maupeou. Dans ces textes, tout en se référant á l'opinion publique, Voltaire ne s'adresse pas à une élite éclairée, mais flatte éhontément les préjugés féodaux des couches diverses de la noblesse. L'article présenté par Eric GATEFIN (Les tourments de l'opinion: hantise du jugement dans l'“'Essai sur les règnes de Claude et de Néron" de Diderot et dans les "Dialogues de Rousseau juge de Jean-Jacques", pp. 41-48) compare l'attitude de Rousseau, méfiante à l'égard d'une opinion qu'il sait d'avance hostile, à celle de Diderot, plus détendue, puisque ce dernier déclare écrire pour la postérité et fait confiance au jugement équitable qui lui aura été réservé. 
Enfin, la troisième unité («Autour de l'opinion publique») renferme trois études. Celle d'Arnaud DECRoIX (L'instrumentalisation politique de l'opinion publique dans les dernières décennies de l'ancien régime, pp. 51-62) porte sur les difficultés de la définition de l'opinion publique et sur l'utilisation de celle-ci par les Parlements ainsi que par le monarque. Decroix évoque la convocation de l'assemblée des Notables, laquelle paradoxalement - constitue le moment où l'opinion publique cède le pas à la nation. Alexandre HYARD (L'opinion publique et les Physiocrates, pp. 63-74) analyse la théorie de l'opinion publique élaborée par les physiocrates, que ceux-ci considèrent comme mode de production de l'unanimité: en fait, pour les disciples de Quesnay, il est inutile d'étendre au peuple le droit de suffrage, puisque l'opinion publique véritable se manifeste essentiellement dans les décisions des propriétaires fonciers. Nicolas VEYSMAN (Une métaphore de l'opinion publique au XVIII siècle: l'hydre de Lerne, pp. 75-90) examine, d'Erasme á Restif, l'histoire et les divers usages de cette métaphore, qui ne disparaîtra qu'à la fin du siècle, remplacée par la métaphore astrale. Pour Veysman, la cause principale de cette disparition est à chercher dans la victoire de l'unité des explications scientifiques sur la multiplicité contradictoire des opinions incapables de former un corps harmonieux.

Deux études constituent le chapitre consacré á Voltaire. Emeka ABANIME (Voltaire et le prince de Timor, pp. 93-116) étudie les causes du refus de Voltaire d'intervenir, en décembre 1768, en faveur d'un Noir Timorien qui se dit prince héritier de l'île. L'article de Michel MERVAud (Tragédie et philosophie dans la correspondance de Voltaire: le cas d'Ivan VI, pp. 117-148) retrace la biographie tourmentée de ce jeune prince, qui figure parmi les six souverains déchus évoqués dans Candide et dont le sort tragique fournit des matériaux à la vision de Voltaire sur la Russie.

$5 \quad$ L'article le plus long du volume est celui de Robert L. DAwson (Naughty French books and their imprints during the long $18^{\text {th }}$ century, pp. 151-239), dans lequel l'auteur, hélas récemment décédé, examine les fausses informations figurant sur les pages de titre des livres 'gaillards' publiés en langue française dans le dernier siècle de l'Ancien Régime. L'étude richement documentée est suivie d'une bibliographie annotée et d'une rapide présentation de tous les livres que l'auteur avait pris en considération.

6 Antony McKenna (Pierre Bayle in the light of new research: faith and reason in the classical age, pp. 243-255), rompant avec l'image d'un Bayle sceptique et fidéiste, met en valeur le rationalisme moral du philosophe de Rotterdam. Ce rationalisme moral, au lieu de lier Bayle aux arminiens et aux sociniens de son temps, le conduit à refuser toute possibilité de compromis entre la foi et la raison ainsi qu'à affirmer la nécessité absolue de la tolérance.

7 Les deux dernières études du volume sont regroupées sous le titre «Nature et Culture». Lyndia ROVEDA (Entre contemplation et observation: l'esquisse de la nature selon Charles Bonnet, pp. 259-276) analyse l'ouvrage apologétique (intitulé La Contemplation de la nature, 1764) du naturaliste génévois. Charles Bonnet s'y efforce de concilier les acquis de la science moderne et les preuves de l'existence de Dieu en greffant sur son texte un certain nombre de notes et d'observations destinées á convaincre les lecteurs les plus sceptiques. Martin WAHLBERG (L'anthropologie des Lumières et le mythe de l'hospitalité lapone-Regnard, Buffon, Maupertuis, Voltaire, Sade, pp. 277-301) analyse les diverses manifestations du mythe selon lequel les Lapons offriraient leurs femmes et filles aux 
voyageurs étrangers. Le mythe en question jouera un rôle fondamental dans le traité $D e$ l'homme de Buffon. 